REVISTA ANDALUZA DE ANTROPOLOGÍA.

NÚMERO 8: TURISMO DE BASE LOCAL EN LA GLOBALIZACIÓN

MARZO DE 2015

ISSN 2174-6796

[pp. 1-18]

http://dx.doi.org/10.12795/RAA.2015.i08.01

\title{
TURISMO DE BASE LOCAL EN LA GLOBALIZACIÓN
}

\author{
Javier Hernández-Ramírez
}

Universidad de Sevilla

\section{1. ¿PASAPORTE AL DESARROLLO?}

Desde las primeras reflexiones y análisis antropológicos del turismo subyace un debate sobre las repercusiones de este fenómeno en la cultura de las sociedades receptoras. No es casual que el primer abordaje antropológico al fenómeno destacara la importancia de este sector como una actividad generadora de cambios culturales (Núñez, 1963). Desde esta mirada, el contacto entre visitantes y nativos desencadena una serie de transformaciones socioculturales que promueven la modernización de las sociedades tradicionales.

En este pionero estudio antropológico del turismo, Theron A. Núñez, Jr. (1963) -un antropólogo de la Universidad de Florida, discípulo de George M. Foster y muy influido por la obra de Robert Redfield- señalaba que el turismo es un laboratorio adecuado para verificar la teoría de la aculturación. Indicaba que hasta entonces el estudio de los cambios culturales derivados del contacto entre culturas solo se había observado en el marco de las migraciones y en la difusión de patrones culturales urbanos en el interior de las sociedades rurales. La aportación principal del trabajo fue resaltar que las relaciones turísticas constituyen también un contexto muy adecuado para profundizar en la aculturación: "I suggest that tourism may be studied and understood within the general framework of acculturation theory” (1963: 347).

En la etnografía de la localidad de Cajititlán (Jalisco, México), Núñez describe una sociedad campesina tradicional relativamente aislada y autosuficiente que, en pocos años, se convierte en un destino turístico. Verifica que las visitas de turistas de fin de 
semana (weekendismo), procedentes sobre todo de Guadalajara y Estados Unidos, y las actividades asociadas al fenómeno (mercantilización, construcción, establecimiento de las instituciones del Estado, mejoras de las comunicaciones, etc.) suponen profundos cambios en todas las esferas de la vida campesina. Según Núñez, el turismo afecta drásticamente a los sistemas de autoridad, los patrones de uso y apropiación de la tierra, las bases económicas, los sistemas de valores, las costumbres y los roles de género. Es tal el desarrollo de la actividad que, en un corto período, todo se ve alterado como consecuencia del impacto turístico y la magnitud del cambio es de tal envergadura que la tradicional sociedad de Cajititlán termina siendo irreconocible.

No hay duda de que el trabajo de Núñez supuso un paso adelante en la consideración del turismo como un legítimo objeto de estudio antropológico por su relevante papel como agente de cambio. Sin embargo, en la etnografía se subraya el carácter del fenómeno como una fuerza externa que desestructura el orden social secular y desencadena el proceso de modernización. Esta particular mirada encaja perfectamente con el marco teórico culturalista y funcionalista dominante en la antropología norteamericana de las décadas de los sesenta, el cual se centraba en los estudios del cambio social a partir del establecimiento de dicotomías entre lo tradicional y lo moderno, y lo rural y lo urbano (Comas y Contreras, 1990). Desde esta perspectiva, la sociedad tradicional es calificada como endogámica, incomunicada, autárquica, autónoma y culturalmente específica, y el turismo se interpreta como un sector exterior que provoca la modernización de este estancado e inmutable modo de vida "folk", que transita a una sociedad moderna, dinámica y abierta.

Dentro de este paradigma de la modernización, posteriores trabajos eludieron o dejaron en un segundo plano las dramáticas repercusiones del proceso sobre la cultura folk y resaltaron que el turismo rescata a estas sociedades de su aislamiento, propicia la integración en la economía mundial, genera empleo, atrae divisas y es la vía idónea para la convergencia con las sociedades más prósperas (Gray, 1970; Matthews 1978; Pearce 1981; Pye and Lin 1983). En un trabajo posterior, Theron Núñez (1992 [1989]) se manifiesta explícitamente a favor del turismo como vía hacia la modernización, generalizando sus efectos benéficos a las naciones que alcanzaron su independencia política tras la Segunda Guerra Mundial: "Durante las últimas décadas, muchos países que han conquistado recientemente su independencia, algunos de los cuales se hallaban postrados en un considerable aislamiento de tipo feudal y han entrado en un mundo mucho más amplio, se han dado cuenta de que su estatus competitivo en una economía monetaria mundial es, en el mejor de los casos, muy precario. El turismo se considera una fuente de ingresos, aparte de algunas otras, que depende exclusivamente de los recursos del propio país; de ese modo, es una autopista hacia el desarrollo y la modernización" (1992: 400).

La mirada optimista de la modernización fue asumida tempranamente por las principales instituciones nacionales e internacionales que contemplaban el turismo como una 
oportunidad y una senda rápida para estimular el desarrollo económico de los países del Tercer Mundo, instando a los mismos a adoptar las medidas necesarias para su impulso y así alcanzar la convergencia con los países avanzados (Crick, 1989).

Este discurso hegemónico y vigente durante décadas en las administraciones públicas, el sector privado y las universidades considera al turismo como una actividad favorecedora del diálogo, la comprensión y el respeto mutuo entre distintos pueblos. En la actualidad estas ideas siguen siendo reiteradamente proyectadas por instituciones gubernamentales, entre las que destaca la Organización Mundial del Turismo (UNWTO), la cual en el preámbulo de su Código Ético Mundial para el Turismo afirma literalmente: "Profundamente convencidos de que, gracias al contacto directo, espontáneo e inmediato que permite entre hombres y mujeres de culturas y formas de vida distintas, el turismo es una fuerza viva al servicio de la paz y un factor de amistad y comprensión entre los pueblos" (1999).

En las Ciencias Sociales son también abundantes los autores que sostienen que el turismo promueve la tolerancia y la comprensión entre las culturas. Entresacamos un par de citas que ilustran el espíritu de lo que San Martín (2003) define como "hipótesis del contacto":

- "No existe mejor puente entre personas, ideas, ideologías, culturas que viajar. Ello puede alimentar la comprensión dentro de un país y entre países” (Powel, 1978: 3).

- "El contacto entre individuos de diferentes grupos crea una oportunidad para el conocimiento mutuo, aumenta la comprensión y la aceptación entre los miembros del grupo que interactúa y consecuentemente reduce el prejuicio intergrupal, conflictos, tensión" (Milman, Reichel y Pizam, 1990: 45).

\section{PRIMERAS VOCES CRÍTICAS}

El enfoque de la modernización encontró su contrapunto en la década de los setenta cuando el desarrollo y la expansión internacional del turismo desvelaron que las repercusiones de la actividad sobre los destinos no encajaban con los pronósticos más optimistas. Ante esta evidencia, en el seno de la antropología emergieron interpretaciones críticas, que denunciaban los efectos perversos de la actividad y rechazaban que ésta fuera la vía adecuada y el atajo para converger con las naciones avanzadas. Esta nueva mirada se enmarcaba -del mismo modo que la modernización anteriormente- en el contexto del desarrollo teórico de la disciplina en el seno de lo que se ha venido a denominar la Teoría de la Dependencia; lo que por otra parte favoreció la institucionalización de la Antropología del Turismo como un campo de estudio específico en la disciplina.

Desde esta perspectiva, el turismo no es la vía hacia la modernización, sino un camino que conduce a la perpetuación de la dependencia socioeconómica y cultural, y en definitiva, 
al subdesarrollo (Britton, 1992 [1982]; Crick, 1989; Erisman, 1992 [1983]; Gaviria et al, 1974; Jurdao, 1990 [1979]; Turner y Ash, 1975). Lejos de favorecer el encuentro intercultural, los autores de esta escuela -que Jafari (2005) denomina "Plataforma Precautoria"- califican el carácter de las relaciones entre nativos y turistas como superficial, transitorio, no recurrente e instrumental, lo que no puede hacer otra cosa que reforzar los prejuicios interétnicos (Boorstin, 1961). En este sentido, Jurdao argumenta que el turismo entendido como un puente que favorece el encuentro intercultural es un mito: "Cuando se habla del turismo como vía de comunicación entre culturas se está falsificando bastardamente la realidad" (...) "Puede haber contactos y tropiezos entre turistas y nativos, pero jamás comunicación” (1992: 25-27).

Visto de este modo, el turismo genera un tipo de relaciones sociales asimétricas; lo que lleva a estos autores a sustituir la teoría de la aculturación, que se centra en el intercambio de préstamos culturales, por la del neocolonialismo, que interpreta que la sociedad más débil (no inferior) asimila los "préstamos culturales" impuestos por la cultura dominante (no superior). En este contexto los actores locales desempeñan un papel pasivo -o adaptativo en el mejor de los casos-, perdiendo el control sobre sus instituciones, costumbres y modos de vida, que entran en un irreversible colapso o metástasis.

Asimismo, los teóricos de esta corriente descalifican las declaraciones y códigos éticos como de una gran ingenuidad teórica y conceptual, pues constituyen bienintencionadas visiones superficiales del fenómeno o -como plantean los más críticos- una retórica altisonante sobre los supuestos beneficios del turismo internacional que oculta los intereses de quienes los formulan (Crick, 1992: 358 [1989]). Al mismo tiempo denuncian a las instituciones internacionales -como el Banco Mundial o la WTO- como cómplices de los intereses de las multinacionales del sector: " $L a$ WTO es un animador instruido por esta industria y por los gobiernos interesados en el turismo" (Richter, 1984, cit. Crick, 1992: 358).

Inspirados en las teorías del imperialismo, del colonialismo y el marxismo, los autores de la Teoría de la Dependencia realizan una importante crítica a la tesis de la modernización, destacando dos argumentos fundamentales:

En primer lugar, el rechazo a la ideología que sostiene que el aislamiento sea una causa explicativa de la pobreza. En oposición a este presupuesto sostienen que son los contactos históricos, que han tomado la forma de relaciones de dominación de unos pueblos sobre otros, los causantes de la desigualdad entre territorios. Afirman además que la mayor integración que propicia el desarrollo del capitalismo está produciendo pobreza y miseria en el mundo, y que sólo unos pequeños sectores de la sociedad se benefician de las ventajas de la globalización (Cardoso y Faletto, 1979; Evans, 1979; Gereffi, 1983; Valenzuela y Valenzuela, 1978). En este sentido, el turismo viene a consolidar y reforzar las históricas relaciones de dominación (Turner y Ash, 1975). 
La segunda crítica consiste en refutar la dualidad "Atraso vs. Desarrollo" propia de la teoría de la modernización, contraponiendo los conceptos de "Subdesarrollo vs. Desarrollo". Desde este punto de vista, rechazan que las naciones pobres lo sean por estar atrasadas social y culturalmente. Argumentan, por el contrario, que son sociedades empobrecidas y subdesarrolladas por haber sufrido las consecuencias negativas del colonialismo y del postcolonialismo. Sostienen, a su vez, que el subdesarrollo en el Sur y el desarrollo en el Norte constituyen "las dos caras de una misma moneda" (Dos Santos, 1970; Frank, 1967), ya que el desarrollo de la metrópolis se produce a expensas de la periferia. De esta manera, la organización económica mundial es interpretada como una estructura modelada al servicio de los inversores extranjeros de los países occidentales, que son identificados como agentes generadores de dependencia y subdesarrollo, pues limitan la capacidad de desarrollo nacional y amenazan el control nacional sobre la economía (Clancy, 1999).

Los estudios de caso de los autores de esta corriente se caracterizan por subrayar una y otra vez las consecuencias perversas del turismo, concebido como una actividad depredadora que mancilla todo lo que toca, destruye el objeto de su deseo y perpetúa el círculo del subdesarrollo en el Sur y el desarrollo en el Norte. Desde esta postura, la expansión turística en los países subdesarrollados no implica mayor dominio local de la actividad, sino todo lo contrario: externalización y fuga de capitales. Esta situación de subdesarrollo estructural supone la entrada en un bucle o círculo de dependencia y pago de deuda del que es muy difícil salir, lo que limita la soberanía de los pueblos sobre sus naciones.

En este sentido, Dennison Nash (1992 [1977]) señala que el turismo es una nueva forma de imperialismo, porque a través de él se expanden intereses económicos y políticos que se imponen en sociedades más débiles. Nash basa su argumentación en la afirmación de que los centros metropolitanos generadores de turistas gozan del control sobre el turismo y lo ejercen en regiones extranjeras: "Este poder sobre los fenómenos turísticos y los diversos desarrollos relacionados con el turismo en el extranjero es lo que hace que los centros metropolitanos puedan ser considerados como imperialistas, y el turismo como una forma de imperialismo" (Nash, 1992: 73). Coinciden con este argumento Turner y Ash (1991 [1975]) que en su ensayo sobre la historia del turismo insisten en esta relación de dominación entre centros emisores de turistas y sociedades receptoras, y sostienen que el turismo es una invasión secundaria, posterior a la invasión militar o a la penetración económica, que consolida la hegemonía del Primer Mundo.

Otra de las críticas más recurrentes e interesantes de este enfoque plantea que la actividad turística mercantiliza la cultura de las sociedades receptoras, transformándola en producto al servicio de los deseos de los turistas consumidores, lo que implica siempre -según esta perspectiva- una interferencia en la continuidad de la tradición cultural, generando el 
extrañamiento de los nativos con sus modos de vida, la dependencia cultural e incluso la aniquilación de la "auténtica" cultura (Greenwood, 1977; Nieto, 1977; Erisman, 1992; Turner y Ash: 1991 [1975]).

En definitiva, ambas corrientes mantenían interpretaciones antagónicas del fenómeno. Mientras que los teóricos de la modernización explicaban el turismo como un signo del progreso de las sociedades y defendían que toda actividad turística es beneficiosa, porque sus efectos positivos son múltiples (rescata del aislamiento, conduce a la convergencia mundial, genera empleo, dinamiza la economía, atrae divisas, contribuye a la creación de nuevas infraestructuras, desencadena efectos territoriales positivos, etc., etc.); los de la teoría de la dependencia enmarcaban el turismo en el desarrollo del capitalismo y sostenían que sus impactos negativos erosionaban las bases socioculturales de las sociedades donde se implantaba (pérdida del control de la propia sociedad sobre la economía y el destino del país, destrucción o mercantilización de las tradiciones, incremento de la deuda, desvertebración de la organización territorial...).

\section{3. ¿UNA CONTROVERSIA IRRESOLUBLE?}

En el seno de la Antropología del Turismo en particular y las Ciencias Sociales en general, la polémica entre teóricos de la modernización y la dependencia se mantuvo casi inalterable durante tres décadas, continuando activa hasta los inicios de la década de los noventa. Aunque en este período la producción bibliográfica sobre turismo crecía sustancialmente, los posicionamientos de los académicos apenas cedían tras las publicaciones de una $\mathrm{u}$ otra corriente. Es sintomático de la persistencia del debate que en 1979 la influyente obra colectiva coordinada por Emmanuel de Kadt fuera imaginativamente titulada: "Turismo, ¿pasaporte al desarrollo?".

Sirvan como ejemplo de la permanencia de esta discusión las siguientes afirmaciones de autores de ambas tendencias:

- En 1982 Britton decía: "Cuando un país del tercer mundo utiliza el turismo como estrategia de desarrollo, acaba inmerso en un sistema global sobre el que apenas tiene control. La industria del turismo internacional es un producto de las iniciativas capitalistas de las metrópolis. Las mejores técnicas empresariales, los mayores recursos y poderes comerciales de las compañias metropolitanas les permiten controlar muchos de los destinos turísticos del tercer mundo" (1992: 303 [1982]).

- Mientras que, en una fecha tan tardía como 1989, Núñez exhortaba a la moderación de los investigadores: "La prudencia exige (...) que la comunidad antropológica resista a la tentación de condenar al turismo en tanto fenómeno intrusivo e innecesario, en tanto fenómeno desculturalizador y explotador. ¿Qué derecho tenemos a decir que la mejora de las redes viarias, los proyectos de purificación de las aguas, la electrificación del medio 
rural, en tanto acicates del desarrollo turístico, no son tan beneficiosos, digamos, para los campesinos y artesanos del medio rural como para sus propios gobiernos y los turistas?" (1992: 411 [1989]).

Como se ve, la vigencia de la controversia revelaba un profundo desencuentro teórico sobre la interpretación del fenómeno caracterizado por visiones antagónicas, inamovibles e irreconciliables. En lo que sí coincidían ambas corrientes era en sostener visiones apriorísticas e ideológicas. Si bien los estudios de caso de una y otra escuela se apoyaban en evidencias más o menos contrastadas, era habitual que a partir de ensayos particulares los autores produjeran generalizaciones sobre el fenómeno, incurriendo así en precipitadas conclusiones de carácter universal, que se ajustaban más a sus ideologías que a una comparación que permitiera matizar atendiendo a la diversidad empírica.

En la actualidad, escasos estudios adoptan explícitamente perspectivas de modernización o dependencia para la interpretación del turismo (Clancy, 1999). Ambas teorías están de capa caída, pero no así el debate entre los defensores y los críticos, el cual sigue vigente. Los primeros, encuadrados en el enfoque que Lea (1988) denomina "conceptualización optimista" y, más tarde Jafari (2005), "plataforma apologética", defiende la potencialidad económica del sector en un mundo global bajo el dominio de la economía de mercado (Santana, 2003). Si bien se matiza la afirmación de que el turismo constituye siempre una panacea, sí se subrayan sus bondades, planteando la necesidad de buscar las condiciones y alternativas que aseguren la sostenibilidad de la industria y hagan viable la reproducción del capital invertido. En este sentido, algunos autores incluso defienden abiertamente y sin complejos las ventajas del turismo de masas (Aramberri, 2011) y otros ven en el sector una oportunidad para el crecimiento económico de zonas periféricas tanto de países desarrollados como subdesarrollados (o en vías de desarrollo, como prefieren calificarlos) bajo las más variadas formas (turismo cultural, patrimonial, de aventura, de naturaleza...). Desde esta renovada perspectiva turístico-céntrica (Saarinen, 2006), el turismo impulsa e intensifica el crecimiento económico y genera empleo como ningún otro sector (Aramberri, 2011) y, al mismo tiempo, revitaliza las comarcas en crisis, pone en valor el patrimonio cultural, protege la naturaleza (Bote Gómez, 1988) y dinamiza social y urbanísticamente los cascos históricos (De la Calle, 2002).

Como contrapunto, también existe hoy una importante escuela crítica al turismo que lo despoja de la santidad que se le atribuye (Blàzquez, 2015: 10). Siguiendo la estela de autores de la teoría de la dependencia (Galán, Martín, Ruiz y Mandly, 1977; Gaviria, et al 1974; Greenwood, 1977 o Jurdao, 1979, entre otros), en España destaca hoy la producción de geógrafos, antropólogos y economistas que analizan el fenómeno sobre todo en el litoral mediterráneo, donde como es bien sabido el desarrollo turístico ha sido especialmente intensivo desde mediados del siglo XX. Los autores denuncian al turismo como un fenómeno asociado a la urbanización, cuya huella ecológica y social es equiparada a la 
de un tsunami devastador (Fernández Durán, 2003). Asimismo, resaltan la voracidad del expansionismo de las cadenas hoteleras españolas en áreas como el Caribe, las cuales se afincan en estos territorios cuando en anteriores enclaves se han agotado las ventajas competitivas de la actividad y los recursos ecológicos al superarse la capacidad de carga (Blázquez, Cañada y Murray, I., 2011; Buades (2006); Fernández-Miranda y Ruiz-Rubio, 2010; Murria, 2015).

\section{EL DEBATE EN LA GLOCALIZACIÓN}

Aunque la polémica subsiste hoy, la actividad turística se ha modificado sustancialmente con respecto a décadas pasadas. Las teorías de la modernización y la dependencia se formularon en un contexto de turismo fordista. En este tiempo dominaba una actividad que, si bien comenzaba a expandirse internacionalmente, aun se desarrollaba estacionalmente en enclaves situados casi siempre en zonas costeras en la modalidad de turismo de masas, hedonista y heliotrópico. Pero desde finales de los ochenta el crecimiento del sector ha sido exponencial y, aunque existen unos focos de atracción más consolidados (Europa, Norteamérica-Caribe, Este-Sudeste Asiático), es indudable la expansión de la actividad a escala prácticamente planetaria. En pocos años se han incorporado numerosos escenarios urbanos y rurales a la geografía turística mundial y se ha ampliado la oferta a un sinfín de posibles prácticas, que tratan de cubrir la demanda de naturaleza, "autenticidad", tradición, modernidad, memoria... de los turistas consumidores.

La diversificación de la oferta se ha traducido en nuevas tipologías turísticas, algunas de las cuales como el ecoturismo en su modalidad de turismo comunitario han sido consideradas verdaderas alternativas al turismo de masas e incluso una vía recomendable para frenar los impactos negativos no solo del turismo, sino también de otras actividades económicas. Este modelo, rebautizado como sostenible o sustentable, ha alcanzado un alto reconocimiento social en las últimas décadas y son muchos los académicos e instituciones que defienden estas propuestas porque consideran que tienen capacidad para superar las contradicciones detectadas.

El fenómeno ha supuesto la proliferación de estudios sobre el turismo y una reedición del debate sobre las repercusiones de la actividad en la cultura. Los investigadores se interesan por el diagnóstico en destinos específicos, cobrando un especial interés el fenómeno del turismo local y/o comunitario, el cual se suele caracterizar por una oferta en la que priman como productos principales la tradición autóctona y el medio ambiente particular. En estos nuevos escenarios de turismo postfordista, la característica común es la comercialización de lo singular del destino local para un mercado global. Es decir, los recursos culturales y ecológicos existentes -y otros que pueden ser recreados e incluso inventados- son transformados en productos para el consumo. 
Reconocer este extremo, es decir, que el turismo consiste enla producción desingularidades para el mercado global (Hernández-Ramírez, 2006) puede todavía generar el rechazo de algunos antropólogos que consideran que dicha práctica supone un atentado contra la continuidad de las esencias culturales. Sin embargo, nos guste o no, lo cierto es que el turismo implica la comercialización de la hospitalidad (Aramberri, 2001; Cohen, 1972; Tucker, 2001; Zarkia, 2011) y la puesta en el mercado de elementos "de color local" sugestivos para el consumo. Pero dejémonos de estériles debates, el problema científico no estriba tanto en la comercialización de la (supuesta) diferencia (como una afrenta contra la "auténtica" cultura), sino más bien en determinar qué grupos e intereses locales y externos controlan dichos procesos de comercialización y cuáles son los objetivos de dichas intervenciones. ¿Quién mercantiliza la cultura o aspectos concretos de la misma?, ¿qué actores seleccionan y patrimonializan elementos específicos de la historia, la tradición, el medio ambiente o el arte de un lugar para transformarlos en productos turísticos?, ¿qué intereses y fines persiguen con estas iniciativas?

Las investigaciones revelan que existe una importante variabilidad empírica. Desde situaciones en las que el turismo genera conflictos internos, dependencia sociocultural, deterioro ambiental, etc.; y contextos en los que, por el contrario, la actividad tiene una efectiva base local que favorece la reafirmación identitaria al tiempo que el etnodesarrollo. Por esta razón, convendría distinguir entre el turismo "en lo local", del turismo "desde lo local". El primero implica que la actividad es dominada por grandes corporaciones, aliadas o no a sectores locales, las cuales producen la imagen del lugar y se embolsan lo fundamental de un gasto turístico cuya reversión es mínima. Por el contrario, el turismo "desde lo local" o "turismo de base local", implica que la sociedad local es la principal gestora y beneficiaria de una actividad que se inserta en la comunidad como un sector más que la enriquece y diversifica. Obviamente, son dos tipos ideales que se sitúan en los extremos de un continuum. No obstante, este marco de análisis empírico puede contribuir a resolver el secular debate desde una perspectiva científica que permita explicar la diversidad empírica existente bajo un sólido marco teórico.

En la comunidad científica, el llamado turismo de base local (o community based tourism) encuentra tanto detractores como defensores, lo cual está relacionado en parte con la variabilidad empírica existente y la carencia de estudios capaces de establecer generalizaciones a partir de la comparación de etnografías particulares. Entre los primeros autores, unos indican que el turismo de base local y/o comunitario es un fenómeno marginal, anecdótico e irrelevante en el marco del turismo internacional (Aramberri, 2011); otros que impulsa contradicciones culturales internas y desigualdades de difícil solución (Ishii, 2012); otros llaman la atención sobre la dificultad para implantar un sector nuevo en sociedades sin experiencia en gestión turística (Gascón, 2013; Stone y Stone, 2011); y, otros, desconfían de sus presupuestos éticos y teóricos (sostenibilidad, 
empoderamiento, participación, inclusión...) al comprobar que sus promotores son agentes externos (empresas, cooperación internacional, ONG,s) que actúan con sus propios intereses no necesariamente coincidentes con los de la sociedad local (Valcuende y de la Cruz, 2009).

En sentido contrario, otros autores analizan otras experiencias de turismo de base local y defienden la hipótesis que sostiene que cuando el turismo es un recurso local y la población participa en los procesos de toma de decisiones, se establecen las condiciones básicas para que se desencadene una espiral de paulatino control comunitario de la actividad, una distribución más equitativa de los beneficios económicos producidos por la misma y una reafirmación de la identidad colectiva y de sus símbolos patrimoniales (Brohman, 1996; Coca, 2012; Hampton, 2005; Mitchel y Reid, 2001; Pereiro, 2007 y 2013; Quintero, 2005; Ruiz-Ballesteros, 2009; Sofield, 2003).

\section{NATURALEZA DEL VOLUMEN ESPECIAL}

Con en este número monográfico de la Revista Andaluza de Antropología centrado en el turismo local en la globalización se persigue contribuir a este debate aportando el análisis de algunos casos significativos. En el volumen se presentan cinco etnografías que toman como unidades de observación realidades socioculturales muy distintas por su localización geográfica (Costa sur de Ecuador, Islas Galápagos, Andalucía, Galicia, Lago Titicaca, Alto Atlas marroquí y Comunidad Valenciana), por el grado de desarrollo turístico (incipiente, consolidado y en decadencia) y, sobre todo, por las variadas repercusiones derivadas de la actividad (deestructuración, reforzamiento de la identidad, desarrollo socioeconómico, pérdida de control sociocultural y político...). Corriendo el riesgo de simplificación asociado a todo esfuerzo de generar taxonomías, los trabajos que aquí se presentan podrían agruparse en dos miradas al turismo local: una primera crítica, heredera de las corriente de la dependencia, que resalta los impactos negativos; y otra posibilista y comunitarista, que interpreta que, en determinados contextos, la actividad tiene potencialidad para promover el desarrollo socioeconómico de las localidades donde se implanta.

Esteban Ruiz Ballesteros, profesor de la Universidad Pablo de Olavide (Sevilla), con amplia trayectoria en el estudio del turismo de base local en América Latina y España, presenta un brillante estudio en el que sintetiza los resultados de investigaciones realizadas en tres unidades de observación muy distintas (Agua Blanca y Floreana en Ecuador, y Alájar en Andalucía). Partiendo de una concepción operativa de comunidad, sugiere que el análisis debiera centrarse en el grado de protagonismo que desempeña la sociedad local en la planificación y gestión turística, atendiendo al proceso de toma de decisiones y a los beneficiarios de la actividad. Bajo este presupuesto, analiza el contexto sociocultural y el 
proceso de desarrollo en estas tres sociedades encontrando tres dinámicas distintas. Una primera que constituye un modelo paradigmático de turismo de base local, pues es la comuna la que, de acuerdo con los procedimientos culturales tradicionales, autogestiona una actividad turística central en la sociedad, ya que representa la mitad de los ingresos de la mayoría de los grupos domésticos. En la segunda dinámica analizada la sociedad local es capaz de reactivarse empoderándose frente al exterior y tomar control sobre su destino. Por último, el estudio de caso de Alájar revela que el desarrollo de la actividad está propiciando un campo de encuentro en el interior de una sociedad polarizada en dos sectores de orígenes distintos (nativos y neorrurales) y estrategias económicas también diferentes (hostelería y restauración). Según el autor, la variabilidad empírica hallada obedece -en gran medida- al distinto grado de estructuración interna y a la capacidad organizativa de las comunidades locales estudiadas.

Xerardo Pereiro Pérez, profesor de la Universidad de Tras-os-Montes e Alto Douro (Portugal) y con reconocidos estudios sobre el turismo comunitario entre los Kuna Yala en Panamá $(2007,2012)$, analiza una muy interesante experiencia de turismo rural de base local en Albá, una aldea situada en el centro de Galicia, donde se promueve la comercialización de los productos locales en el marco de un proyecto de agroturismo ecológico. La experiencia supone la integración de la actividad turística en las formas de vida tradicionales, lo que para el autor representa un cambio de paradigma que supone el paso "del turismo rural sin agricultura" a una "agricultura con turismo". Es decir, se produce una interrelación no subordinada entre las actividades "de siempre" y el turismo, que se incorpora al tejido sociocultural como una actividad más, contribuyendo además a la dinamización económica. La iniciativa particular descrita en el trabajo muestra la potencialidad de un modelo en el que se establecen relaciones de complementariedad entre el turismo y las actividades tradicionales en una dinámica de retroalimentación positiva.

En un sentido bien distinto al de Pereiro y Ruiz-Ballesteros, Jordi Gascón -investigador del Instituto de Altos Estudios Nacionales de Ecuador- contribuye al debate con su análisis bien fundamentado del desarrollo turístico en la Isla Amantaní en el lago Titicaca (Perú). En su etnografía demuestra cómo el desarrollo turístico se ha convertido en una fuente de conflictos en el interior de la comunidad indígena kichwa, al enfrentar intereses individuales con otros colectivos. El ascenso socioeconómico y político de los sectores beneficiarios del turismo (lancheros) ha desencadenado una nueva estructuración social, al tiempo que promovido la segregación de la comunidad en dos grupos religiosos. La adscripción mayoritaria de los lancheros a una determinada creencia (adventismo) les ha eximido de los gravosos gastos que supone el sistema de fiestas, el cual siempre actuó como mecanismo de redistribución y nivelación social. Esta acción, contraria a los patrones tradicionales, se enmarca en una estrategia de acumulación que acentúa la 
desigualdad en el interior de la comunidad, permite la ampliación del negocio y una más eficiente articulación de los empresarios indígenas con el mercado.

Otra visión crítica del turismo en contextos locales es la que ofrece María Jesús Berlanga en su estudio sobre los impactos que genera en el grupo étnico de los AïtHaddidou que habita en el Alto Atlas Oriental de Marruecos. La etnografía muestra que el turismo local, promovido en gran medida por las instituciones del Estado, desencadena una serie de procesos que, en su conjunto, suponen la desarticulación de la cultura tradicional. En primer lugar, la opción por el turismo implica la acentuación de desigualdades sociales preexistentes tanto entre las dos fracciones de este grupo étnico como entre géneros, incrementando el poder de los hombres. La implantación del turismo se traduce, en segundo lugar, en el surgimiento de nuevas formas de inequidad entre los sectores sociales que monopolizan los beneficios del turismo y los que son ajenos al sector, así como entre jóvenes, con mayor formación y conocimiento de idiomas, y ancianos, que ven mermado su estatus social. Asimismo, la actividad se traduce en la penetración de valores individualistas que sustituyen a los tradicionales, fracturando aún más el anterior equilibrio al introducirse nuevos comportamientos sociales. Por último, el control ejercido por el poder político de los rituales festivos y de los elementos más significativos del patrimonio cultural son mecanismos tanto de atracción turística como estrategias de poder que persiguen erosionar la integridad étnica, así como ejercer el control sobre la población AïtHaddidou y sus instituciones tradicionales. La intervención exterior sobre el patrimonio con fines turísticos está suponiendo, según la autora, la adaptación del legado cultural al gusto turístico y la espectacularización de las ceremonias tradicionales. Estas actuaciones implican el distanciamiento paulatino de la sociedad con su legado histórico y tradicional que abandona y rechaza sus costumbres y símbolos en un claro proceso de aculturación.

Cierra el monográfico, el trabajo realizado por Carmona-Zubiri, Travé-Molero y NoguésPedregal de la Universitas Miguel Hernández sobre el turismo en Elche, localidad que tiene la particularidad de reunir tres elementos reconocidos por la UNESCO como Patrimonio de la Humanidad (Palmeral, Misteri y Museo Escolar de Pusol). A estos tres bienes patrimoniales se añade un cuarto elemento: la escultura ibérica de la Dama de Elche, que, por su valor de antigüedad, es considerada por la población como el símbolo más emblemático de la identidad local. En el trabajo se verifica un típico caso de turismo "en lo local" en el que el papel de la sociedad en la definición del destino turístico es limitado, asumiendo las autoridades locales el protagonismo principal, mediante una estrategia política de producción y promoción de una imagen de marca-ciudad atractiva que toma a tres de estos elementos como principales recursos turísticos del municipio, así como símbolos sobresalientes de la identidad ilicitana. En esta labor, los bienes seleccionados son resignificados de acuerdo con una estrategia de marketing que persigue 
adaptarlos a los gustos de los turistas globales, aunque esto suponga su desvinculación del contexto local. Sin embargo, el Museo de Pusol, como experiencia patrimonial activa y referente del vínculo de Elche con su pasado agropecuario, queda excluido de la oferta, por cuanto no se ajusta al modelo urbano que se desea promocionar, generando una imagen sesgada del lugar y, como indican los autores, "un nuevo marco de sentido para la identidad ilicitana”.

Los artículos que conforman este monográfico revelan la diversidad empírica que supone la plasmación del turismo en destinos locales específicos y muestran que el problema científico de la Antropología del Turismo actual consiste en explicar esta complejidad.

En el volumen se comprueba que el método etnográfico característico de la Antropología Social tiene capacidad para diagnosticar de primera mano la realidad de las sociedades que reciben turistas, aportando valiosos datos e informaciones directas sobre las estrategias de los grupos domésticos y sectores empresariales, así como de las alianzas y tensiones públicas en relación con el control y los procesos de toma de decisiones sobre el turismo. Este enfoque empírico y analítico, que se acerca a la perspectiva nativa, a las interpretaciones locales sobre el fenómeno y a las prácticas sociales a través de la observación participante, es una herramienta privilegiada para abordar esta cuestión.

Sin embargo, el riesgo de este enfoque es incurrir en un excesivo particularismo que sobrevalore la dimensión local y dé escasa relevancia o ignore el contexto geoestratégico de los territorios donde se localizan los destinos. Ante ello, la Antropología del Turismo debe encarar también otros factores fundamentales, tales como determinar el protagonismo de los estados y gobiernos regionales y locales (intervencionismo/liberalismo), el grado de desarrollo de los países, así como su posición en el orden económico y político regional y mundial. Paralelamente, es importante definir qué agentes económicos impulsan las actividades (multinacionales, administraciones -locales, regionales, nacionales o supranacionales-, empresariado local, regional o nacional, ONGs) y la capacidad de control que tienen sobre las decisiones económicas y políticas.

Esta perspectiva, que atiende simultáneamente a lo local y lo global, puede contribuir a discernir en qué casos concretos el turismo promueve el encuentro y el desarrollo, y en qué otros, genera dominación y dependencia. Esta cuestión, que históricamente se ha resuelto desde enfoques apriorísticos y sumamente ideológicos, se transforma en un problema científico a determinar que nos rescata del artificial debate que supone optar entre la aceptación o el rechazo al turismo. Liberado del análisis valorativo, este enfoque centra su interés en determinar los agentes, conflictos y alianzas, que intervienen en una realidad social dada para así averiguar qué factores configuran el desarrollo turístico en un momento y lugar concretos. De este modo, de ser la variable independiente, el turismo se convierte en la dependiente (Clancy, 1999). 


\section{REFERENCIAS BIBLIOGRÁFICAS}

Aramberri, Julio (2001) "La trampa del anfitrión. Un paradigma en la teoría del turismo". Annals of Tourism Research en español 3(2), pp. 259-286.

Aramberri, Julio (2011) Turismo de masas y modernidad. Un enfoque sociológico. Madrid: Centro de Investigaciones Sociológicas.

Blázquez, Macià (2015) "Prólogo". En Iván Murria Capitalismo y Turismo en España. Del "milagro económico" a la "gran crisis". Barcelona: Alba Sud.

Blázquez, M., Cañada, E. y Murray, I. (2011) "Búnker playa-sol. Conflictos derivados de la construcción de enclaves de capital transnacional turístico español en El Caribe y Centroamérica". Scripta Nova 15(368).

Bote Gómez, Venancio (1988) Turismo en espacio rural. Rehabilitación del patrimonio sociocultural y de la economía local. Madrid: Popular.

Boorstin, Daniel. J. (1997 [1961]) The image: a guide to pseudo-events in America. New York: Atheneum.

Britton, Stephen G. (1992 [1982]) "La economía política del turismo en el Tercer Mundo". En Francisco Jurdao (comp.) Los mitos del Turismo. Madrid: Endymion, pp. 301-337.

Brohman, John (1996) "New directions in tourism for third world development". Annals of TourismResearch 23(1), pp. 48-70.

Buades, Joan (2006) Exportando paraísos. La colonización turística del planeta. Palma: La Lucerna.

Cardoso, Fernando H. y Faletto, Enzo (1979) Dependency and development in Latin American. Berkeley: University of California Press.

Clancy, Michael (1999) “Turismo y Desarrollo. El caso de Méjico". Annals of Tourism Research en español 1(1), pp. 2-10.

Coca, Agustín (2012) "Turismo comunitario como estrategia de resistencia en el Alto Napo Ecuatoriano". En Valcuende del Río, José María (coord.) Amazonía. Viajeros, turistas y poblaciones indígenas. Tenerife: Colección Pasos Edita, nº 6, pp. 261-292.

Cohen, Eric (1972) “Toward a sociology of international tourism”. Social Research 39, pp. 164-182.

Comas, Dolors y Contreras, Jesús (1990) "El proceso de cambio social". Agricultura y Sociedad 55, pp. 5-70.

Crick, Malcolm (1989) "Representations of International Tourism in the Social Sciences: sun, sex, sights, saving, and servility”. Annual Review of Anthropology 18, pp. 307-344. 
De Kadt, Emanuel (coord.) (1991) Turismo: ¿Pasaporte al desarrollo?. Madrid: Endymion. De la Calle Vaquero, Manuel (2002) La ciudad histórica como destino turístico. Barcelona: Ariel Turismo.

Dos Santos, Theotonio (1970) “The structure of dependence". American Economic Review 60, pp. 231-236.

Erisman, H. Michael (1992 [1983]) “Turismo y dependencia cultural en las Antillas". En Francisco Jurdao (comp.) Los mitos del Turismo. Madrid: Endymion, pp. 179-213.

Evans, Peter B. (1979) Dependent Development: the alliance of Multinational, State, and Local Capital in Brazil. Princenton: Princenton University Press.

Fernández Durán, Ramón (2003) El Tsunami urbanizador español y mundial. Sobre sus causas y repercusiones devastadoras, y la necesidad de prepararse para el previsible estallido de la burbuja inmobiliaria. Madrid: Virus.

Fernández-Miranda, Ramiro y Ruiz-Rubio, Rodrigo (2010) Políticas públicas, beneficios privados. Mecanismos, políticas y actuaciones públicas para la globalización del turismo. Madrid: Foro de Turismo Responsable.

Frank, Andre G. (1967) Capitalism and undervelopment in Latin American. New York: Monthly Review Press.

Galán, J. J., Martín, A., Ruiz, J. y Mandly, Antonio (1977) Costa del Sol. Retrato de unos colonizados. Madrid: Campo Abierto Ediciones.

Gascón, Jordi (2013) "The limitations of community-based tourism as an instrument of development cooperation: the value of the Social Vocation of the Territory concept". Journal of Sustainable Tourism 21(5), pp. 716-731.

Gaviria, Mario et al. (1974) España a go-go. Turismo charter y neocolonialismo del espacio. Madrid: Turner.

Gerefi, Gary (1983) The pharmaceutical industry and dependency in the Third World. Princenton: Princenton University Press.

Gray, H. Peter (1970) International Tourism: International Trade. Lexington: Health Lexington Books.

Greenwood, Davydd J. (1992 [1977]) "La cultura al peso: perspectiva antropológica del turismo en tanto proceso de mercantilización cultural". En Valene L. Smith (coord.) Anfitriones e invitados. Antropología del Turismo. Madrid: Endymion, pp. 257-279.

Hampton, Mark P. (2005) "Heritage, local communities and economic development". Annals of Tourism Research 32(3), pp. 735-759. 
Hernández-Ramírez, Javier (2006) "Producción de singularidades y mercado global. El estudio antropológico del turismo". Boletín Antropológico 66, pp. 21-50.

Ishii, Kayoko (2012) “Theimpact of ethnic tourism on hill tribes in Thailand". Annals of Tourism Research, 39(1), pp. 290-310.

Jafari, Jafar (2005) "El turismo como disciplina científica". Política y Sociedad 42(1), pp. 39-56.

Jurdao, Francisco (1990 [1979]) España en venta. Madrid: Endymion.

Jurdao, Francisco (comp.) (1990) Los mitos del Turismo. Madrid: Endymion,

Lea, J. (1988) Tourism and development in the Third World. New York: Routledge.

Matthews, Harry (1978) International Tourism: a Political and Social Analysis. Cambridge: Schenkman.

Milman, A., Reichel, A. y Pizam, A. (1990) "The Impact of Tourism on Ethnic Attitudes: The Israeli Egyptian Case". Journal of Travel Research 29(2), pp. 45-49.

Mitchell, Ross E. y Reid, Donald G. (2001) "Community integration: Island tourism in Peru”. Annals of Tourism Research 28(1), pp. 113-139.

Murria, Iván (2005) Capitalismo y Turismo en España. Del "milagro económico" a la "gran crisis". Barcelona: Alba Sud.

Nash, Dennison (1992 [1977]) "El turismo considerado como una forma de imperialismo". En Valene L. Smith (coord.) Anfitriones e invitados. Antropología del Turismo. Madrid: Endymion, pp. 69-91.

Nieto, José Antonio (1977) “Implicaciones socioeconómicas, ecológicas y culturales del turismo. Su impacto en una pequeña comunidad". Cuadernos de Realidades Sociales 13, pp. 67-80.

Nuñez, Theron A. Jr. (1963) "Tourism, Tradition and Acculturation: Weekendismo in a Mexican Village". Ethnology 3, pp. 347-352.

Nuñez, Theron A. Jr. (1992 [1989]) "Los estudios del turismo dentro de una perspectiva antropológica”. En Valene L. Smith (coord.) Anfitriones e invitados. Antropología del Turismo. Madrid: Endymion, pp. 397-413.

Pearce, Douglass (1981) Tourism Development. Harlow: Longman Group.

Pereiro, Xerardo (2007) Los impactos del turismo en Kuna Yala (Panamá). Madrid: Ramón Areces.

Pereiro, Xerardo (2013) "Los efectos del turismo en las culturas indígenas de América Latina”. Revista Española de Antropología Americana 43(1), pp. 155-174. 
Pereiro, X; De León, C.; Martínez Mauri, M.; Ventocilla, J. y Del Valle, Y. (2012) Los turistores Kunas. Antropología del Turismo étnico en Panamá. Palma. Universidad Islas Baleares.

Powell, John (1978) The Canadian Tourism Industry: A Report by the Sector Task Force. Ottawa.

Pye, Elwood y Lin, Tzon-Biau (1983) Tourism in Asia: the economic impact. Singapore: National University of Singapore.

Quintero Morón, Victoria (2005) "El patrimonio intangible como instrumento para la diversidad cultural. ¿Una alternativa posible?”. En Carrera, Gema y Dietz, Gunther (coord.) Patrimonio Inmaterial y Gestión de la Diversidad. Sevilla: Consejería de Cultura, pp. 68-83.

Ruiz-Ballesteros, Esteban (2009) Agua Blanca. Comunidad y Turismo en el Pacífico ecuatorial. Quito: Abya Yala.

Saarinen, Jarkko (2006) "Traditions of sustainability in tourism studies". Annals of Tourism Research, 33(4), pp. 1121-1140.

San Martín, Jesús (2003) "Relaciones interculturales en el contexto turístico”. Boletín de Psicología, 77, pp. 19-38.

Santana, Agustín (2003) "Mirando culturas: la Antropología del Turismo”. En Rubio Gil, Ángeles (coord.) Sociología del Turismo. Barcelona: Ariel Turismo, pp. 103-125.

Sofield, Trevor H. B. (2003) Empowerment for Sustainable Tourism Development. Oxford: Elseiver.

Stone, Lesego S. y Stone, Tibabo M. (2011) "Community-based tourism enterprises: challenges and prospects for community participation. Khama Rhino Sanctuary Trust, Bostwana”. Journal of Sustainable Tourism 19(1), pp. 97-114.

Tucker, Hazle (2001) “Turistas y Trogloditas'. Negociando la sostenibilidad”. Annals of TourismResearch en Español 3(2), pp. 313-339.

Turner, Louis y Ash, John (1991 [1975]) La horda dorada. El turismo internacional y la periferia del placer. Madrid: Endymion.

UNWTO (1999) Código Ético Mundial para el Turismo. Santiago de Chile.

Valcuende del Río, José María y De la Cruz Quispe, Liz (2009) “Turismo, poblaciones locales y organizaciones no gubernamentales: un análisis de caso en Madre de Dios (Perú)”. Pasos. Revista de turismo y patrimonio cultural 7(2), pp. 179-196.

Valenzuela, J. Samuel y Valenzuela, Arturo (1978) "Modernization and Dependency. Alternatives perspectives in the study of Latin American Undervelopment". Comparative Politics 10, pp. 543-557. 
Zarkia, Cornélia (2011 [1996]) "Philoxenia: recibiendo a turistas "no a huéspedes" en una isla griega". En Boissevain, J. (ed.) Lidiar con turistas. Reacciones europeas al turismo de masas. Barcelona: Bellaterra, pp. 187-222. 